\title{
Estimation of the Parameters Concerning with the Growth and Survival Processes of Shirasu from Its Size Composition*1
}

\author{
Kei TAKIZAWA *2 \\ (Received September 22, 1980)
}

\begin{abstract}
Depending upon the analysis of the size composition drawn from catch the conditions of some exploited fish population have often been studied, and the size composition of some larval fishes may surely take hold of the revelation of their survival and growth processes in the sea. This paper treats of these matters by inspecting the size compositions drawn from the catch by the small drag net with the aid of mathematical models of a exponential function or a stochastic process.

Almost all the size composition may show the one of a cohort with the individual variation in growth though there appears the error due to the method of sampling or measurement. In the consequence of the quadratic regression application to the size composition the survival period of the cohort is detected to be about 60 days and the mortality coefficients averaged through this period have become the values within the range of $0.0250-0.0418(1 /$ day $)$. The coefficients which indicate the variance of individuality in the logarithmically transformed total length have the values of ten to the minus fourth power, that are supported by the studies in another fishes rearing.
\end{abstract}

The shirasu which is the larva of some littoral fishes such species as anchovy Engraulis japonica, round herring Etrumues micropus and sardine Sardinops melanosticta is generally captured by the small drag net called "Patchi-ami" along the coast of Tosa Bay ${ }^{12}$. These larval fishes have the transparent body without pigments and are at most $50 \mathrm{~mm}$ in total length ${ }^{2)}$. And within this range the size compositions of anchovy, round herring and sardine have the points of similarity that there appears a remarkable mode. Fig. 1 shows some examples (in 1979 Aug. 24) of the size composition of larval anchovy which were collected from the catch of ten seiners that belong to Akaoka fisheries cooperative association.

It may be considered that these samples except a few are drawn from the independent population of shirasu cohort though there appears the error due to the method of sampling or measurement. For the histogram which is got through summing up each element of the samples shows a simple bell-shape distribution function (Fig. 1) and the central limit theorem declares that the histogram of the population will approximate to the normal distribution as the samples of a certain distribution function increase in number ${ }^{32}$.

The size composition drawn from catch has been considered to contain much information about ecological aspects of the exploited fish population. In this paper, considering that the survival and growth processes of fish are concurrent phenomena the author will discuss the treatment of the size composition and the survival process of larval anchovy that appears in the consequence of the foregoing way.

\section{Analytical Methods}

To grasp the actual condition of fishery resources, the estimation of parameters about the growth or survival of fishes has often been argued. For instance, merits and demerits of von Bartalanffy's growth equation have been discussed by many fishery scientists ${ }^{4-7}$. The former, in brief, is that $K$ which is the growth coefficient of Bartalanffy's equation is based on the facts of physiology or bioenergetics directly and prosperously ${ }^{()}$, on the other hand the latter is that this equation shows at best a special case among them, etc ${ }^{4,7}$.

Regardless of these arguments, it is allowed that there are the parameters which only represent the development of growth or survival of larval fish against the time after its hatching out. For it is a well-known fact that an experimental rearing

*1 This work was orally presented to the Annual Meeting of Japan. Soc. Sci. Fish. at Fukuoka in October, 1980.

*2 Department of Fisheries, Faculty of Agriculture, Kyoto University, Sakyo-ku, Kyoto 606, Japan (㝛沢 敬：京都大学费学部). 


\section{TOTAL LENGTH $(\mathrm{mm})$}
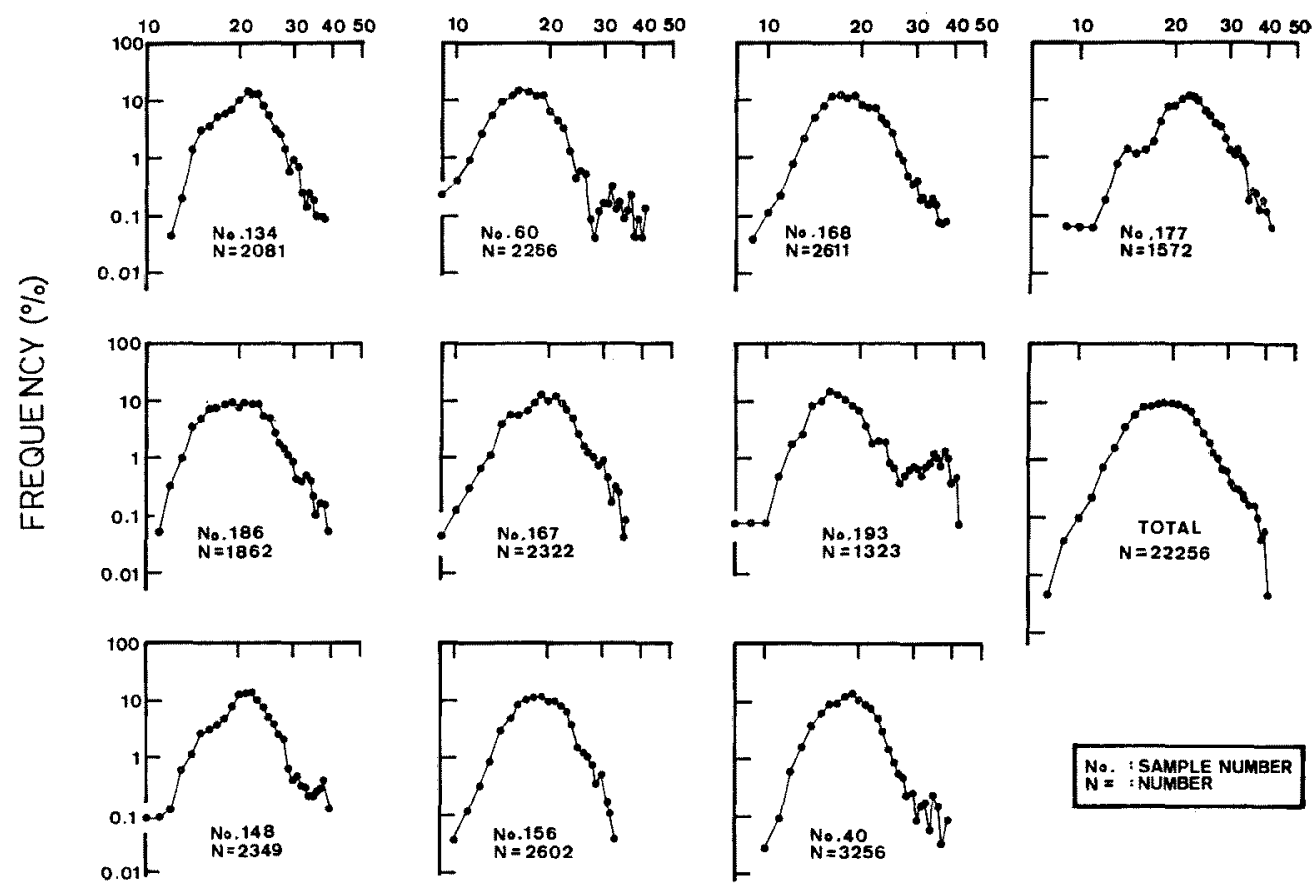

Fig. 1. Size compositions of larval anchovy which were collected from the catch by the small drag net. Both the scales of the total length (abscissa) and the frequency (ordinate) are represented logarithmically.

cohort decreases in number and grows in length or weight as it survives ${ }^{8,8)}$ though it is surely under a certain physiologic and bioenergetic conditions. From this point of view, the transition of survival and growth of larval anchovy may be empirically expressed with those parameters as follows,

$$
N(t)=N_{0} e^{-\mu t}
$$

and

$$
l\left(t^{\prime}\right)=l_{0} e^{a t^{\prime}}
$$

respectively ${ }^{10,11)}$. Eq. (1) shows the survival process with $\mu$ which is the mortality coefficient and Eq. (2) the growth process with the parameter $a$ relating to the growth speed in length, where $N_{0}$ and $l_{0}$ are their initial conditions respectively. Distinctly these equations show that an anchovy cohort decreases exponentially in number and an individual increases alike in length within the range of the given total length. And here let Eq. (2) be settled by taking $l_{0} 3.33(\mathrm{~mm})$ and $a 0.0267$ (1/day) respectively from the experimental data ${ }^{10)}$.

In many studies about the growth of the ex- perimental rearing cohort the individuality in growth have been apt to be standardized and neglected as errors consequently, but NAKAMURA and KASAHARA ${ }^{12-14)}$ and YAMAGISH ${ }^{15\rangle}$ referred considerably to this problem through the cautious experiments of some fishes rearing. And if the size composition reflects the one of an anchovy cohort with the variance of individuality in growth, its transition may be expressed by the population balance model ${ }^{10)}$. Namely this model shows that the transition of the size composition of a cohort is expressed with the partial differential equation of the parabolic type. Denoting the frequency distribution of size $L(=\log l)$ at time $t$ by $C(t, L)$, it is written as,

$$
\frac{\partial C}{\partial t}+a \frac{\partial C}{\partial L}=-\mu C+b \frac{\partial^{2} C}{\partial L^{2}}
$$

where $a$ is the mean growth speed of its constituent individuals in logarithm of length as in Eq. (2) and $b$ is a coefficient which indicates the diffusivity of the growth among them. This equation shows that the transition of the frequency distribution is subject to both the number of the 
individual and the growth diffusivity effect ${ }^{18\rangle}$. If all the individual is $L_{0}$ at $t=0$, this can be written as,

$$
C(0, L)=\delta\left(L-L_{0}\right)
$$

where $\delta(L)$ is the Dirac's delta function and $L_{0}=$ $\log l_{0}=1.20$ from Eq. (2). Considering Eq. (4) which is the initial condition, Eq. (3) can be solved as follows,

$$
C(t, L)=\frac{1}{2 \sqrt{\pi b t}} \exp \left\{-\mu t-\frac{\left(L-L_{0}-a t\right)^{2}}{4 b t}\right\}
$$

or

$$
\begin{aligned}
\log \{C(t, L)\}= & -\frac{1}{4 b t}\left(L-L_{0}-a t\right)^{2} \\
& -\mu t-\log 2 \sqrt{\pi b t}
\end{aligned}
$$

Eq. (6) shows that log (frequency of size composition) is represented by a quadratic function of log (total length). This equation also considers the survival process expressed by the Eq. (1).

Depending upon the hypothetical process as mentioned previously three parameters of $t, \mu$ and $b$ can be estimated by considering the quadratic regression of the logarithmically transformed size composition curves ${ }^{17}$. And such may be the adequate method for the estimation that the data for analysis are only the larger than the modal individual, which is due to the selectivity of the net for the smaller ${ }^{18)}$, and are occasionally restricted to the smaller but dominant cohort.

\section{Results and Discussion}

The parameters estimated from the above hypothetical model are shown in Table 1. The estimates $t$ which indicates the survival period of the modal individual that is detected by the quadratic regression of the sample are about 60 days or two months. The study on its spatial and temporal distributions in the sea during this period is the pending subject that is quite interesting to note.

The mortality coefficients $\mu$ in this study show the averaged values through the survival period as mentioned previously and have become the values within the range of $0.0250-0.0418$ ( $1 /$ day) as shown. These values are smaller than those in the preceding study ${ }^{10}$ ) in which the estimation of $\mu$ would be held by the method of the linear regression in the size composition. Such a method
Table 1. Parameters estimated of the larval anchovy cohorts by the size compositions drawn from the catch of ten seiners

\begin{tabular}{cccc}
\hline Sample No. & $t$ (day) & $\begin{array}{c}\mu \times 10^{2} \\
(1 / \text { day })\end{array}$ & $\begin{array}{c}b \times 10^{4} \\
\left(1 / \text { day }^{2}\right)\end{array}$ \\
\hline No. 134 & 62.7 & 2.75 & 3.06 \\
No. 186 & 67.5 & 4.04 & 2.24 \\
No. 148 & 69.2 & 3.38 & 1.30 \\
No. 60 & 59.7 & 4.18 & 2.09 \\
No. 167 & 58.5 & 3.03 & 4.70 \\
No. 156 & 62.5 & 3.51 & 2.82 \\
No. 168 & 63.3 & 4.16 & 2.43 \\
No. 193 & 59.5 & 4.09 & 1.81 \\
No. 40 & 57.2 & 2.50 & 3.82 \\
No. 177 & 64.4 & 2.92 & 4.07 \\
\hline
\end{tabular}

indeed considered the selectivity of the net for the smaller individual, but not so much as the larger escaper from the net. For the preceding analyses were carried out with the data drawn from the vertical hauls of the larval or plankton net with a few meters aperture, so not a few larger escapers may have been underestimated in the size composition ${ }^{19}$, that may provide such a large mortality. And actually Patchi-ami often captures even the adult fishes of sardine, anchovy or some other larger species.

Though the numerical estimation of the variance in growth among individuals has scarcely been taken up for discussion, $b$ in Eqs. (3), (5) and (6) are detected to have the values of ten to the minus fourth power. And these estimates are supported by the studies in the rearing of red sea bream*1 Pagrus major, black sea bream*1 Acanthopagrus schlegeli and Japanese striped knifejaw*2 $O p$ legnathus fasciatus as follows. The data were drawn from the samples of ten or twenty individuals every time which were thinned out from the cohort during the experiments for about 40 days running. Table 2 shows the estimates of $a$ and $b$ of each species respectively. From the comparison between Tables 1 and 2, the estimates of anchovy show somewhat dispersively but have the similar orders to those of these fishes and hence the values estimated may be significant.

As proposed here the analysis of the size composition by the population balance model which considers the survival-growth process of the organism dynamically is quite significant to express the ecological aspects of the larval fishes of some species. Another studies about the size com-

*1 M. Matsuoka, unpublished data.

*2 Laboratory of Aquaculture, Nagasaki Pref. Inst. of Fish., unpublished data. 
Table 2. The estimates which indicate the mean growth speeds in total length and the coefficients of diffusivity in growth among the constituent individuals of three species cohorts reared for about 40 days. $r$ indicates the correlation coefficient

\begin{tabular}{ccc}
\hline Species & $a \times 10^{2}(1 /$ day $)$ & $b \times 10^{4}\left(1 /\right.$ day $\left.^{2}\right)$ \\
\hline $\begin{array}{c}\text { Red sea bream*1 } \\
\text { Pagrus major } \\
\text { Black sea bream*1 } \\
\begin{array}{c}\text { Acanthopagrus schlegeli } \\
\text { Japanese striped knifejaw*2 } \\
\text { Oplegnathus fasciatus }\end{array}\end{array}$ & $4.75(r=0.991)$ & $1.67(r=0.963)$ \\
\hline$* 1 \quad$ M. MAtsuoka, unpublished data, & $* 2$ & Laboratory of Aquaculture, Nagasaki Pref. Inst. of Fish, unpublished data.
\end{tabular}

position is to estimate some parameters regarding the bumpy distribution of size composition as meaningful in itself ${ }^{18,2 \cdot-24)}$. In spite of these studies the author has presented the analysis with the quadratic regression of size compositions, because except a few there is no evidence that the bumpy histogram of total length in shirasu catch is actually meaningful. And considering that the data for analysis were measured by the unit of millimeter, the size composition may represent rather the histogram of a single cohort with the statistical error than the bumpy histogram of meaningful in itself, Which method being chosen, they may be noted that the parameter estimation of a definite equation is almost "a partial solution" and just a mathematical problem, and that the equation which reflects satisfactorily the ecological aspect of shirasu has been set up considerably there. In addition to this, the estimates are not reasonable until they can illustrate the actual conditions of shirasu which are detected through some other methods or experiments, even if the improvement in the computer programs will get rid of the troubles in calculations.

Finally the author wishes to thank Dr. Takeru KITAHARA and Mr. Satoru Toda for initiating his interest in the studies about shirasu fishery. He also wishes to acknowledge the great convenience by Dr. Akira OChIaI, Mr. Masurao Hirata and Mr. Tadao Nakamoto for the settlement of the practical problems.

\section{References}

1) K. Takizawa: Bull. Japan. Soc. Sci. Fish., 46, 831-835 (1980).

2) R. IshiYama: J. Fish. Sci, 40, 1-21 (1950).

3) J. H. CuRTiss: Annuals. of Math. Stat., 13, 430433 (1942).

4) W. KNIGHT; J. Fish. Res. Board Can., 25, 1303-
1307 (1968).

5) K. Onodera: Bull. Japan. Soc. Sci. Fish., 36, 266-275 (1970).

6) T. KAWAI; Bull. Japan. Soc. Sci. Fish., 36, 289 296 (1970).

7) D. A. Roff: Can. J. Fish. Aquat. Sci., 37, 127129 (1980).

8) R. LASKer, H. M. Feder, G. H. ThellaCker, and R. C. MAY: Mar. Biol, 5, 345-353 (1970).

9) E. D. Houde and B. J. Palko: Mar. Biol., 5, 354-358 (1970).

10) K. Kondo: Katakuchiiwashi no Seitai to Shigen, Suisan Kenkyu Sohsho 20, Nihon Suisanshigen Hogo Kyokai, 1971, pp. 10-16.

11) K. Kondo, Y. Hori, and K. Hiramoto: Maiwashi no Seitai to Shigen, Suisan Kenkyu Sohsho 30, Nihon Suisanshigen Hogo Kyokai, 1976, p. 43.

12) N. NAKamura and S. Kasahara: Bull. Japan. Soc. Sci. Fish., 21, 73-76 (1955).

13) N. Nakamura and S. Kasahara: Bull. Japan. Soc. Sci. Fish., 21, 1022-1024 (1956).

14) N. Nakamura and S. Kasahara: Bull. Japan. Soc. Sci. Fish., 22, 674-678 (1957).

15) H. Yamagishl: Res. Popul. Ecol., 11, 14-33 (1969).

16) R. W. Thompson and D. A. Cauley: J. theor. Biol., 81, 289-307 (1979).

17) G. Strang: Linear Algebra and Its Applications, 2nd ed., Academic Press, New York, 1980 , pp. $103-150$.

18) M. OKa: Bull. Fac. Fish. Nagasaki, 2, 8-25 (1954).

19) G. I. MurPhy and R. I. ClutTER: Fishery Bull., 70, 789-798 (1972).

20) A. Sudd: Bull. Japan. Soc. Sci. Fish., 20, 460468 (1954).

21) S. TANaKa: Bull, Japan. Soc. Sci. Fish., 20, 681-688 (1954).

22) S. Tanaka: J. Fish. Res. Board Can., 19, 11431159 (1962).

23) P. D. M. Macdonald and T. J. Pitcher: J. Fish. Res. Board Can., 36, 987-1001 (1979).

24) H. Imabayashi: Bull. Japan. Soc. Sci. Fish., 46, 419-426 (1980). 